\title{
Research on the Education of China's One-Child Family
}

\author{
Yang Song, Peng Nai* \\ ${ }^{1}$ Law School of Yunnan University of Finance and Economics, Yunnan, China \\ ${ }^{*}$ Corresponding author
}

Keywords: Ecology of Education; Family Education; Only-Child.

\begin{abstract}
Family planning policy was introduced in 1979, it has been 37 years since 2016 which fully open two kids, while after 2016, many families are no longer one-child family, but it is still the main force of our country for the next 20 years , and in this way, "The persistance of the one-child education" only child's education is particularly important. Based on 317 questionnaires published at home and abroad, this paper discusses the problems and causes of family education of one-child, and tries to put forward relevant countermeasures to improve family education of one-child in China from the perspective of ecology of education.
\end{abstract}

\section{The Only Child's Special Background}

The implementation of the family planning policy is based on the specific historical background and conditions. When the first batch of only children were born, China's social economy, life and system had been gradually recovered from the disaster of ten years. After the reform and opening up, China was developing at a rapid speed, and cultural education and ideological exchange were paid unprecedented attention. The parents of those who experienced pain and regret during China's turbulent decade faced their only child with a natural sense of compensation, both material and spiritual, generous and urgent[1].This kind of compensation is not only the compensation for the child, hoping to give him more and better material or spiritual satisfaction, but also the compensation for himself, hoping his child can realize his dream that he wanted to achieve but could not achieve.

\section{The Only Child's Family Background}

After the family planning policy, the family structure of the Chinese society began to change, gradually replaced by the small family pattern, family mode gradually turned to the "421" family today, because each family have only one child, the passage of time, the dominant form of family business with children as the center of the structure, only children as the future of the family, he could not dream, condensed the generation and countries experiencing at this time, a lot of system are in need of repair reconstruction, social for the guidance of the family education is almost a blank[2].As a result, in many families, there are some opposite educational effects, namely, the imbalanced material compensation and effective education for children[3]. 


\section{Social Background of Only Child[4]}

For China at that time, this is an era of opportunity and challenge coexist, absorb advanced technology and culture at the same time, also the introduction of international competition, the first batch of one-child is on one side under the impact of foreign culture, and grown up under more intense competition, they face the broader world, enjoy a more favorable conditions, at the same time, they are also under indirectly or directly to give their pressure in modern society, the pressure is what their parents did not suffer[5].

\section{Analysis on the Problems and Causes of the Only-Child Family Education in China}

\subsection{Only Child Family Education Problem}

Table 1. Statistical term correlation

\begin{tabular}{|c|c|c|c|c|c|c|}
\hline & & $\begin{array}{c}\text { Strong } \\
\text { dependence }\end{array}$ & $\begin{array}{c}\text { Lack of } \\
\text { responsibility }\end{array}$ & $\begin{array}{l}\text { Family } \\
\text { quality }\end{array}$ & $\begin{array}{c}\text { Family } \\
\text { education } \\
\text { concept }\end{array}$ & $\begin{array}{c}\text { Family } \\
\text { education } \\
\text { environment }\end{array}$ \\
\hline \multirow[b]{2}{*}{$\begin{array}{l}\text { Strong } \\
\text { dependence }\end{array}$} & Pearson & 1 & $-.401^{* *}$ & $-.518^{* *}$ & -.009 & .015 \\
\hline & $\begin{array}{l}\text { Significance } \\
\text { (bilateral) }\end{array}$ & & .000 & .000 & .894 & .834 \\
\hline & $\mathrm{N}$ & 211 & 211 & 211 & 211 & 211 \\
\hline \multirow{2}{*}{$\begin{array}{l}\text { Lack of } \\
\text { responsibility }\end{array}$} & $\begin{array}{l}\text { Pearson } \\
\text { correlation }\end{array}$ & $-.401^{* *}$ & 1 & $.667^{* *}$ & $.441^{* *}$ & .129 \\
\hline & $\begin{array}{l}\text { Significance } \\
\text { (bilateral) }\end{array}$ & .000 & & .000 & .000 & .061 \\
\hline & $\mathrm{N}$ & 211 & 211 & 211 & 211 & 211 \\
\hline \multirow{3}{*}{$\begin{array}{l}\text { Family } \\
\text { quality }\end{array}$} & $\begin{array}{l}\text { Pearson } \\
\text { correlation }\end{array}$ & $-.518^{* *}$ & $.667^{* *}$ & 1 & $.277^{* *}$ & $.141^{*}$ \\
\hline & $\begin{array}{l}\text { Significance } \\
\text { (bilateral) }\end{array}$ & .000 & .000 & & .000 & .040 \\
\hline & $\mathrm{N}$ & 211 & 211 & 211 & 211 & 211 \\
\hline \multirow{3}{*}{$\begin{array}{l}\text { Family } \\
\text { education } \\
\text { concept }\end{array}$} & $\begin{array}{l}\text { Pearson } \\
\text { correlation }\end{array}$ & -.009 & $.441^{* *}$ & $.277^{* *}$ & 1 & $.216^{* *}$ \\
\hline & $\begin{array}{l}\text { Significance } \\
\text { (bilateral) }\end{array}$ & .894 & .000 & .000 & & .002 \\
\hline & $\mathrm{N}$ & 211 & 211 & 211 & 211 & 211 \\
\hline \multirow{3}{*}{$\begin{array}{l}\text { Family } \\
\text { education } \\
\text { environment }\end{array}$} & $\begin{array}{l}\text { Pearson } \\
\text { correlation }\end{array}$ & .015 & .129 & $.141^{*}$ & $.216^{* *}$ & 1 \\
\hline & $\begin{array}{l}\text { Significance } \\
\text { (bilateral) }\end{array}$ & .834 & .061 & .040 & .002 & \\
\hline & $\mathbf{N}$ & 211 & 211 & 211 & 211 & 211 \\
\hline
\end{tabular}

**. There was a significant correlation at the.01 level (bilateral).

*. There was a significant correlation at the 0.05 level (bilateral). 
From the analysis of the questionnaire, it can be seen that the one-child show some outstanding problems:

First,strong dependence. This is mainly reflected in poor self-care ability and poor psychological autonomy. In the 317 questionnaires, $39.17 \%$ of the students choose to ask their parents for help when encountering big setbacks, and $43.32 \%$ of the children are accustomed to turn to their parents for help when making decisions, instead of considering decisions by themselves.Second,lack of responsibility. In my survey, only $30.88 \%$ of the children have a detailed plan for their future, and most of them have only a vague positioning. Many college students do not know what they want to do for a long time after graduation, and they habitually accept the arrangement of their families.

What is the cause of these problems, this paper tried to test the correlation analysis, as shown in the table 1.

Combined with the data in the figure above and the existing studies, we can verify experts' researches on the problems existing in the only child, that is, the quality of the family is related to the dependence of the child. The lower the quality of the parents, the less independent the child will be. And the lack of sense of responsibility of children is related to the concept of family education. The more single the concept of family education is, the more likely children are to lack of sense of responsibility.

\subsection{New Findings - Three Factors that Influence Each Other}

At the same time, in some new conclusions we found, through observation and analysis of the data in the black part of the table, we found that in addition to the indirect correlation between family education environment and the education process of the only child, the quality of parents and the concept of family education are also subtly related.First, family own quality and family education concept, there is a significant positive correlation between the family their own quality, the higher the family of the higher education idea, a study shows, in parents' own quality higher family, its education philosophy is more reasonable and appropriate because when parents have enough reserves to the knowledge of the education, it has the education idea of get corresponding improvement[6].Second, there is a significant positive correlation between family quality and family education environment, that is, the higher the family quality is, the better the family education environment will be, which is similar to the concept of family education[7].Third, there is a significant positive correlation between family education concept and family education environment, that is, the higher the family education concept is, the better the family education environment is.To sum up, we can see that the three factors of family education environment, family education concept and parents' own quality are actually correlated with each other and show a positive correlation, that is, "when you are higher, I am higher; when you are lower, I am lower".

Why does this happen? This is because the "environment" in the growth process of the only child is the main part of the nutrient supply, family education environment, education concept and parents' own quality, is the background of the only child's growth[8].Studies have shown that when parents high quality of its own, he is more reasonable than their parents have appropriate education idea, under the guidance of this concept of education, can form a more proper family education environment[9], they prefer to go to a full range of foster children, more conscious let children to be independent to do some housework, more willing to sit down and carefully listen to the children's idea of equality of.

\section{The Countermeasures to Perfect the Education of the Only-child Family in our Country}

\subsection{Existing Solutions[10]}

The solutions to the problems in single-child family education are generally divided into the 
following two categories:One,make corrections from a parent's perspective. First of all, it is necessary to correct parents' educational ideas, educational methods and educational goals to make them more appropriate and reasonable, so as to set a positive example for children and create a scientific and reasonable educational environment for children.Second,fix it from your child's perspective. This requires that we should pay attention to the cultivation of children's practical ability, strengthen the cultivation of children's autonomy and independent ability, pay attention to the coordinated development of children's moral, intellectual, physical and aesthetic aspects, and improve children's personality education[11].

\subsection{Defects of Existing Countermeasures}

It is not hard to see, the different scholars and experts on the one-child family education problems and countermeasures of different views and opinions are different, they will appear in the one-child family education in accordance with their respective focus on the research of the problem of cutting out, just starting from the view of a certain subject, just around the relatively specific education way and education method, and ignore the local education exists in the environment outside the broader, more powerful social structure factors, they ignored China's one-child problem of multiple attributes[12].In this way, it is easy to divide the problem into too scattered and independent parts, and it is easy to cause incomplete understanding of the problem, so that the proposed solutions are biased and cannot really solve the problem.

\subsection{To Further Improve the Thinking Angle with the Idea of Ecology of Education}

So, I think, the one-child family education problems in the research, we can try the education ecology point of view, and pay attention to the influence of social environment on the one-child family[13], from the perspective of the overall environment to observe family education problems, specifically from three aspects cuts are needed to solve the problem.

The first,start with the relationship between subject and environment

The main body and the environment under the perspective of education ecology is specific and relative, when you stand in the perspective of children, children are the main body, parents and other family members is the main growth environment, children learn the nutrient growth environment, parents as environment for children to supply the required nutrients, and successful family education does not supply and obtain the harmony and unity between don't appear "glut" or "supply", how to achieve the harmony of supply and demand?On the one hand, from the perspective of "environment", families of only children are mainly "421" families. The change of family structure makes many educational factors infiltrate into families, and the consequence is the increase of heterogeneity of family education[14].Therefore, how to integrate family education resources, how to resolve the heterogeneity of family increase, is an important issue; In addition, we also need to pay attention to the compensation psychology of parents. Excessive compensation psychology inevitably brings excessive attention and investment. When their psychological expectation increases, but they find that the investment cannot get corresponding return, their sense of loss and frustration will affect their children's education[15]. On the other hand, from the perspective of "subject", it is necessary for parents and schools to work together to consciously cultivate children's sense of responsibility, independent ability, collective consciousness, tolerance spirit, etc., and to properly and reasonably help them understand their shortcomings and correct them.

The second,start with the environment.Here is mainly to solve the problem of the education concept of the parents, the first thing to change the parents of only children, one child "alone" is the core of the family education, but "alone" is not the problem, how to understand "alone" is the key, this requires parents in line with a common heart to treat their children, control their own compensation psychology, don't spoil and spoil the child too much; The second is the changing 
parents incorrect concepts, such as investment will pay off psychology, education is not the industrial production, to expand reproduction, education is a fire makes sweet malt work, according to the different of each child at the same time, investment in education is also same will get different output, such as parents to control eating again, exorbitant expectation is counterproductive, especially when some unrealistic goal, when eating, the parents will feel frustrated, the children's confidence will hit; Finally, the single family lifestyle should be changed, and the content of education should be rich and colorful. In addition to the learning of cultural classes, children should also cultivate their own interests and hobbies. The era of "not listening to things out of the window and reading only the sages and sages" has long been in the past.

Third, start with the subject.From the point of view of ecology of education, the core of single-child family education is their niche specialization[16].A lot of research is pointed out that only children's independent ability is poor, the lack of a sense of community, more selfish, this is because their niche is specialized, the only children in the family, at the same level of "species" is only a their own, they did not own brothers and sisters, they take all the resources, there is no pressure to survive, especially when a big supply of resources, this greatly reduces their survival ability, make some problem due to the niche specialization further continuous fermentation.

So, the pressure is on to reconstruct only child's education ecological niche, its essence is to solve the one-child niche "uniqueness", of course, change this state without competition best and the quickest way is to introduce a competitor, a two-child policy is in a process of introducing the competitors, it will cause a sense of crisis, most of the one child policy to consciously strengthen own various aspects ability.

For families with only children who have grown up or are unable to have a second child, it is time to limit or reduce the supply. The reason why there are still many "boomerang kids" in today's society is that parents are still providing unlimited nutrition. The only children are used to getting or always getting more nutrition from their parents, so they lose the idea of competition and gradually lose the ability to compete.

\section{References}

[1] Luo feng. Comparison and Suggestions of three major disciplines of contemporary family education research methods [J]. Exploration of youth, 2008

[2] Xu yunhua. Study on single-child family education [J]. Journal of mudanjiang university of education, 2010, no. 2:82-83

[3] Miao jiandong. Sociology of family education [M]. Nanjing normal university press, December, 1999

[4] Feng xiaotian, social adaptation of the first generation of only children [J]. Education research, 2005

[5] Zheng yanping. Analysis on the problems in China's single-child family education [N]. Science and education BBS, 2004, no. 1:45 -- 47

[6] Li yalin. Research on urban single child family education [N]. Theory

[7] Feng xiaotian. China's one-child study: review and prospect [J]. Journal of jianghai, 2002, no. 5

[8] Hong Ming. Analysis on the problems of single child family education [J]. Theory edition, 2002, no. 2:15-22

[9] Liu fei. Research on family education of only child [J]. Times education, no. 2:193-194 
[10] Deng chuanzhi, xu rong. Family sociology [M]. Beijing: China social sciences press, 2001.76

[11] Feng xiaotian. Socialization process and results of singleton adolescents [M]. Chinese social sciences, 2000

[12] Liu xinchao, social development and existing problems of the only child [J]. Science and technology information, 2007

[13] Liu yuzhi, One-child problem in Chinese cities [J]. Population research, 1997

[14] Feng xiaotian, China's one-child problem -- a multidisciplinary analysis framework [J]. Zhejiang journal, 2008

[15] Yin jianli. Why our children become little emperors [M]. Beijing: communication university of China press, 2010

[16] Cai yangmei. Current situation and problems: the "only child" research in China in recent five years [J]. China youth research, 2002

[17] Liu wen. Analysis of "421" family structure formed by single child [J]. Journal of shenyang agricultural university (social science edition), 2006

[18] Shi yan. A review of China's one-child studies [J]. Chinese youth studies, 2008

[19] Wang hui-juan. Attaching importance to family education is the necessity of modern education [J]. China science and technology innovation guide, 2009

[20] Zhang li. The phenomenon of the dislocation of parents' education concept and the strategy of correcting deviation [D]. Central China normal university, 2007

[21] Xiong ying. Confusion and research on the education of single children in China [J]. Journal of southwest normal university: philosophy and social science edition, 1996

[22] Su songxing. Single child: the development from new national conditions to new subjects [J]. Contemporary youth studies, 1994 